\title{
Academic Identity Formation and Motivation Among Ethnic Minority Adolescents: The Role of the "Self" Between Internal and External Perceptions of Identity
}

\author{
Jamaal S. Matthews \\ Montclair State University
}

\author{
Meeta Banerjee \\ University of Michigan
}

\author{
Fani Lauermann \\ University of Bonn
}

\begin{abstract}
Identity is often studied as a motivational construct within research on adolescent development and education. However, differential dimensions of identity, as a set of internal values versus external perceptions of social belonging, may relate to motivation in distinct ways. Utilizing a sample of 600 African American and Latino adolescents $(43 \%$ female; mean age $=13.9)$, the present study examines whether self-regulated learning (SRL) mediates two distinct dimensions of academic identity (i.e., value and belonging) and mastery orientation. This study also examines whether self-efficacy moderates the mediating role of SRL between identity and mastery. Results show evidence for moderated mediation between SRL and academic self-efficacy. Selfregulated learning played its strongest mediating role between belonging and mastery and for low-efficacy students specifically.
\end{abstract}

Identity can be a pathway toward understanding achievement motivation during adolescence. Conceptualizing identity formation as the individual's attempt to define one's self through personal values as well as perceived social interconnectedness (Osborne \& Jones, 2011; Schachter \& Rich, 2011), adolescence researchers have engaged in the study of identity as a catalyst for motivated action, particularly within the context of schools (Eccles, 2009; Faircloth, 2012; Kaplan \& Flum, 2012). Moreover, for historically marginalized populations such as African American and Latino youth, identity-based explanations have dominated the research literature in an attempt to explain persistent underachievement trends.

Adolescence, particularly around sixth grade through the transition into high school, presents itself as a unique developmental stage for understanding emergent identity for two main reasons. First, neurological development in adolescent cognition as well as changes in social consciousness play an important role in adolescents' propensity toward identity construction and meaning making (Erikson, 1968; Harter, 2006). Essentially, this is when youth

Correspondence concerning this article should be addressed to Jamaal S. Matthews, 2133 University Hall, Montclair State University, 1 Normal Ave., Montclair, NJ 07043. Electronic mail may be sent to matthewsj@mail.montclair.edu. begin to actively manage and think critically about who they are and their place in the world. Second, perceptions of the self and identity formed during adolescence have powerful implications for longterm educational and career-related outcomes (Barber, Eccles, \& Stone, 2001). However, African American and Latino adolescents in urban schools often contend with unique social challenges and cultural stigma that can influence their self-perceptions and academic motivation (Smalls, White, Chavous, \& Sellers, 2007; Wong, Eccles, \& Sameroff, 2003). Such issues may amplify the significance of this developmental period for socially marginalized youth and indicate a need to unpack the processes supporting their academic motivation.

Focusing specifically on African American and Latino adolescents in urban schools, we establish the relation of two distinct dimensions of academic identity (value and belonging) for achievement motivation. Moreover, we seek to understand how "self" mechanisms, namely self-regulated learning (SRL) and academic self-efficacy, explain this relation. Achievement motivation is operationalized by mastery goal orientation, which reflects a learning

(C) 2014 The Authors

Child Development (C) 2014 Society for Research in Child Development, Inc. All rights reserved. 0009-3920/2014/8506-0018

DOI: $10.1111 /$ cdev. 12318 
orientation that emphasizes persistent effort, continual self-improvement, mastery of learning content, and adaptive responses to failure (Midgley et al., 1998). First, we model the mediating role of SRL, illustrating how identity relates to mastery. Second, we propose that academic self-efficacy moderates the mediational pathway via SRL, elucidating for whom academic identity is related to mastery. Neither academic self-efficacy, the belief in one's capabilities to execute and perform well on academic tasks, nor SRL, the self-directed planning and monitoring of strategies to meet academic goals, is a novel concept (Pintrich, 2000). However, nuanced understanding is still lacking with regard to how SRL and academic self-efficacy work together to support motivational processes among minority groups such as African American and Latino adolescents. Furthermore, singular or narrow conceptions of identity (e.g., value or self-concept) have perpetuated persistent disidentification claims for marginalized adolescents, failing to consider the multiple dimensions of identity concurrently.

To address these concerns, this study considers diverse facets of identity, as well as how SRL and self-efficacy interact to inform motivation, all during the sensitive period of early to middle adolescence. This study aims to illustrate how the propensity for African American and Latino adolescents to engage in effortful learning behaviors differs across different perceptions of identity (i.e., value and belonging) and interacts with self-efficacy beliefs simultaneously. We expect struggling students' perceptions of school belonging, beyond their value of education, to be a preeminent predictor of the effortful regulatory strategies that support a mastery orientation for learning. We examine these issues within the context of urban schools, which tend to serve high percentages of African American and Latino students and historically have struggled with engagement and achievement among these populations.

\section{Conceptualizing Academic Identity}

A domain identification approach to academic identity describes how identities are dynamically formed through social interaction as well as the negotiation of values and competencies for constructing an identity that is consistent and harmonious (Blumer, 1969; Osborne \& Jones, 2011). Based on this perspective, when a person receives performance-related feedback from his or her environment, that information - if perceived as valid - can be internalized, allowing the person to identify with a domain that he or she values. Whereas positive feedback is rewarding, negative feedback about a valued domain can lead to psychological vulnerability and perceived threat (Steele, 1997). As a result, adolescents may separate their sense of worth from a threatening domain, which can negatively impact their motivation in that domain.

Two noteworthy literatures have emerged from this framework that attempt to describe the identity formation and motivation of ethnic minority youth specifically. The first frames identity as internally negotiated (e.g., "Being a good student is important to me"), while the second depicts identity as externally supported (e.g., "My relationships at school make me feel like I belong there"). The first body of work has predominantly consisted of comparative studies by racial group, focusing on the internally negotiated components of academic identity (e.g., value of education, academic centrality, selfconcept). This literature typically finds African American and Latino youth to be in deficit on these internal values compared to White American youth, which may explain academic underperformance among these populations (Griffin, 2002; Morgan \& Mehta, 2004; Ogbu, 1991; Taylor \& Graham, 2007). However, these findings have confronted ample criticism, which we summarize below, indicating a need for a more balanced identity framework that considers varied aspects of identity, beyond values, as well as their interactive role in informing adolescent motivation (Harris, 2006; O'Connor, 1997; Tyson, Darity, \& Castellino, 2005).

The second body of literature focuses on the external attributes that scaffold academic identity (e.g., school belonging, social interconnectedness), and generally has found that marginalized and underachieving adolescents tend to rely on socioecological supports within schools for negotiating academic identities and scaffolding achievement motivation (Faircloth, 2009; Faircloth \& Hamm, 2005; Goodenow \& Grady, 1993; Honora, 2003; Nasir, Jones, \& McLaughlin, 2011; Walton \& Cohen, 2011). Although the domain identification approach situates identity formation at the intersection of both the individual and the social world, much of its empirical outgrowth has predominantly focused on one to the exclusion of the other. As Ashmore, Deaux, and McLaughlin-Volpe (2004) point out, however, a multidimensional conceptualization of identity that includes not only internal attributes (i.e., value) but also ecological interactions such as social belonging more adequately captures identitybased processes. Hence, in this study we evaluate two dimensions of identity simultaneously, value and belonging, which align with the aforementioned 
internal versus external frames of identification with academics.

\section{Identity as Internal Perceptions of Value}

The value dimension (coined as importance by Ashmore et al., 2004) of identity formation is an internally negotiated dimension of identity. It reflects the degree of value or importance a person attaches to an aspect of his or her self-concept. In this study, we assess a value of education through intrinsic achievement values, which is the perceived importance, interest, or enjoyment of engaging in academic tasks. These values are integral to the identification process, reinforcing self-understanding and scaffolding academic identity formation (Eccles, 2009; Wigfield \& Eccles, 2000). Developmental research suggests that intrinsic values develop in specificity over the adolescent years, ultimately reflecting enduring qualities that are construed as self-defining (Eccles, 2009; Wigfield \& Cambria, 2010). Research has also shown that intrinsic values tend to decline with age during adolescence as academic responsibilities, rigor, and evaluation increase (Wigfield \& Eccles, 2002).

This downward trend is particularly evident among African American and Latino adolescents. For example, compared to White American and Asian adolescents, research reveals that academic performance plays a less important role in shaping the academic behaviors and decisions of African American and Latino adolescents (Griffin, 2002). Others have demonstrated that African American and Latino males, compared to their female and White American counterparts, were most likely to nominate low-achieving and poorly behaved peers as someone they admire and respect, suggesting a devaluing of achievement (Taylor \& Graham, 2007). Furthermore, the widely discussed yet ardently contested work of John Ogbu (1978, 1991, 2003) describes "cultural inversion" as the inability of involuntary minority youth to value the ideals of a culture in which they are marginalized.

Despite such discouraging trends, two important caveats must be considered. First, a growing body of studies within the value literature directly challenges the notion that ethnic minority adolescents undervalue academic success. This research has shown that many African American and Latino youth have positive perceptions of school for upward mobility, possess greater affect toward school than White American youth, embrace the struggle toward becoming achievement oriented, and are not predominantly oppositional toward achievement values
(Harris, 2006; O'Connor, 1997; Tyson et al., 2005; Wright, 2011). Second, several scholars have noted that the value literature reflects a failure to understand the complexity of social identities as they relate to achievement and motivation, particularly for marginalized youth (O'Connor, 1997; Spencer, Noll, Stoltzfus, \& Harpalani, 2001). This implies that other aspects of self-perceptions beyond achievement values, such as feelings of belonging, may explain learning and engagement processes for minority youth. Thus, due to its focus on a narrow dimension of academic identity, the value literature may inappropriately reinforce a deficiency paradigm for African American and Latino adolescents.

\section{Identity as External Perceptions of Belonging}

Alternatively, the literature on belonging (also coined attachment and interconnectedness, Ashmore et al., 2004) describes an ecologically sensitive component of identity that reflects wanting to belong to a group that is viewed as part of the individual's self-concept. The need to belong is particularly salient during the transition to adolescence and feelings of social connectedness during adolescence are well recognized as a key protective factor for positive youth development (Lerner et al., 2005). The desire to develop identity and agency outside of the family context leaves youth hungry for social interactions in other arenas (e.g., school) that can provide information about who they are and their place in society. Similar to intrinsic values, empirical data indicate that, with age, school belonging declines for adolescents, at least as early as sixth grade (Anderman, 2003; Witherspoon \& Ennett, 2011). Unfortunately, feelings of school belonging are challenged most during middle and high school (i.e., early to middle adolescence), when institutions become more impersonal, more discipline oriented, competitive, and overcrowded (Eccles \& Roeser, 2011). This problem is particularly incisive for urban institutions that serve predominantly minority adolescents (Anderman, 2002).

Although school belonging is important for all adolescents, some evidence suggests that it may have unique function for marginalized and underachieving adolescents (Faircloth \& Hamm, 2005; Sanchez, Colon, \& Esparza, 2005; Singh, Chang, \& Dika, 2010; Walton \& Cohen, 2011). For example, Faircloth and Hamm (2005) found school belonging played a stronger role (full mediation) between selfefficacy and performance for African American and Latino youth compared to White American and Asian youth (partial mediation). Furthermore, one 
intervention aimed at increasing belonging revealed enduring achievement and mental health benefits for African American adolescents, but not their White American counterparts (Walton \& Cohen, 2011). Finally, a high school study found school belonging predicted academic engagement for African American youth, while internal perceptions of self-concept was a stronger predictor of engagement for White American youth (Singh et al., 2010).

There are various reasons why belonging may be especially important for the social development of African American and Latino youth. For example, due to the marginalized existence of African Americans and Latinos throughout American educational history (e.g., school segregation, the civil rights movement, and current issues of educational inequity), a strong sense of school belonging may be more difficult to facilitate. Indeed, African American adolescents in urban secondary schools, particularly males, are most likely to experience declines in support and quality relationships and are also disproportionately placed in remedial and low-rigor classes (Thomas \& Stevenson, 2009). Considering that such social challenges coincide with a sensitive developmental period when the need for belonging is especially salient, it is not surprising that studies show African American and Latino youth display more mistrust of school personnel and have difficulties buying into school roles and expectations (Honora, 2003; Roderick, 2003; Sanchez et al., 2005). Hence, the belonging literature intimates that motivation and performance trends for historically marginalized youth can be at least partially attributed to the perceived relational quality of their school environments.

Thus, given their importance for successful scholastic functioning, especially among African American and Latino youth, the present study examines perceptions of both internal and external (i.e., value and belonging) aspects of identity concurrently. In the following section, we focus on "self" mechanisms, such as SRL and self-efficacy, which may explain how and for whom identity - defined as value and belonging - relates to achievement motivation.

\section{The Role of the "Self" Within Identity Formation: SRL and Self-Efficacy}

Beyond value and belonging, various scholars (e.g., Bandura, 2001; Eccles, 2009; Oyserman, 2007; Paris \& Paris, 2001) discuss how strategies of behavioral enactment (i.e., self-regulation) and perceptions of academic tasks as doable (i.e., self-efficacy) help consolidate identity as well as support achievement motivation. SRL has generally been described as the planning, monitoring, and evaluating of one's self in order to attain an academic goal (Pintrich, 2000). However, pursuing an academic goal may not be the only reason an individual decides to regulate his or her behavior. One's perceived identity, along with the desire to reinforce and express that identity, can also move an individual to regulate his or her behavior in ways that are consistent with that identity (Oyserman, 2007; Paris, Byrnes, \& Paris, 2001). Furthermore, SRL may not only be an outcome of identity strivings, but simultaneously a means to scaffold one's orientation around learning, for example, one's mastery orientation (Paris \& Paris, 2001). Accordingly, SRL is one likely mechanism by which identity is translated into a mastery orientation for learning, and may mediate the relation between identity and mastery.

Self-efficacy - the belief to be able to accomplish designated tasks (Bandura, 2001) - should also be considered, since it has been identified as an important facilitator of SRL (Schunk \& Ertmer, 2000; Zimmerman, Bandura, \& Martinez-Pons, 1992) and academic motivation (Eccles, 2009). Adolescents with low academic self-efficacy are most likely to psychologically disengage from academic activities, become susceptible to feelings of futility, cope less well under stress, and be less likely to regulate their own learning (Bandura, Barbaranelli, Caprara, \& Pastorelli, 1996; Caprara et al., 2008). However, when adolescents are confident about their academic abilities (i.e., self-efficacy) they act volitionally to satisfy their needs (i.e., self-regulatory behaviors), which in turn consolidates identity, enhances mastery orientation for learning, and ultimately reinforces self-efficacy, creating a self-empowerment cycle (Zimmerman \& Kitsantas, 2005). Thus, the relation between identity and SRL may depend on students' self-efficacy beliefs.

Nonetheless, maintaining a high sense of efficacy during transitions into middle and high school can be difficult. Beginning in early adolescence, self-efficacy and efficacy to self-regulate are both in decline (Caprara et al., 2008; Eccles \& Roeser, 2011). Though the capacity for regulatory control increases during adolescence (Luna, Padmanabhan, \& O'Hearn, 2010), learning how to manage new biological, educational, and social transitions simultaneously can frustrate efficacy and overburden regulation, making adolescents feel unable to establish personal control. Many urban minority youth also confront cultural stigma and low teacher expectations that further hamper self-efficacy (Lynn, Bacon, Totten, Bridges, \& Jennings, 2010).

Despite these difficulties, we believe that belonging may be a unique predictor of academic effort, 
even during a sensitive period where efficacy may be in decline. In fact, feelings of belonging may help students navigate the pervasive effects of low efficacy. Though some work suggests such buffering effects (Honora, 2003), none directly tests whether the relation between belonging, SRL, and motivation differs for high- versus low-efficacy youth. Furthermore, of the available studies that examine the interactive effects of self-efficacy and SRL for academic outcomes, hardly any consider these processes primarily among African American and Latino adolescents. Hence, the present study assesses this interplay between SRL and self-efficacy across the value and belonging dimensions of identity to understand whether these distinct frames of self-perception relate to SRL and mastery differently for high-efficacy versus low-efficacy students. We ground this analysis within the context of adolescent identity formation for urban minority youth, as our hope is to strengthen the empirical literature on achievement motivation among historically marginalized populations.

\section{Present Study}

In light of the growing literature on academic identity formation among marginalized youth, as well as the limitations embodied within, the present study examines two research questions. First, does SRL mediate the relation between academic identity (i.e., value of education and school belonging) and mastery orientation? Mediation implies that a third variable gives an account for why the relation between the independent and dependent variables exists (Baron \& Kenny, 1986). In other words, do adolescents' effortful regulatory strategies explain how identity predicts motivation?

Hypothesis 1a: We expect value and belonging will have a direct positive relation to mastery orientation.

Hypothesis $1 \mathrm{~b}$ : We also expect SRL to be positively related to mastery.

Hypothesis 1c: When SRL is included as a mediator working in tandem with identity, the direct effect of identity on mastery will diminish in significance, suggesting the positive effect of identity on mastery unfolds (partially or fully) via SRL.

In our second question, assuming there is evidence for mediation, we examine moderated mediation where the mediational role of SRL for identity and mastery is moderated by academic self-efficacy (see Figure 1). Moderated mediation is evident when the mediation between the independent and dependent variables is contingent upon a fourth moderating variable (Preacher, Rucker, \& Hayes, 2007). In other words, does SRL play a different role in the association between identity and mastery for more efficacious compared to less efficacious students?

Hypothesis 2a: We propose self-efficacy will moderate the path between identity and SRL, such that value and belonging will relate to SRL differentially based on one's level of selfefficacy.

Hypothesis 2b: We also expect efficacy to moderate the relation between SRL and mastery. For both hypotheses, we expect the mediational role of SRL between belonging and mastery to be strongest for low-efficacy adolescents and weakest for high-efficacy adolescents. This implies that, controlling for value, a sense of belonging would be most predictive of self-regulation and motivation for students who lack academic efficacy (Figure 1b).

Student gender, ethnicity, grade level, and mother's level of education all have the potential to predict considerable variation in the hypothesized constructs and models. Thus, all inferential analyses controlled for these constructs.

\section{Method \\ Sample}

The sample consisted of 600 African American and Latino adolescents in the 6th (27\%), 8th (35\%), and 10th grades (37\%) in a cross-sectional survey design $\left(M_{\text {age }}=14\right.$ years). There were 339 (56.5\%) male and 258 (43\%) female participants. Youth were recruited across seven middle and high schools in Harlem and the South Bronx, New York City. These included three middle schools (Grades 6-8), three high schools (Grades 9-12), and one secondary school with Grades 6-12, all Title I funded. The self-identified ethnicity of the participants was African American or Black (38\%), Dominican (26\%), Puerto Rican (18\%), Latino without ethnic delineation $(9 \%)$, Mexican (5\%), biracial $(1 \%)$, other $(<1 \%)$, or missing $(2 \%)$.

Information pertaining to family background was provided by $64 \%$ of the participants' parents. Of those, $25 \%$ of mothers had less than a high 
(a)

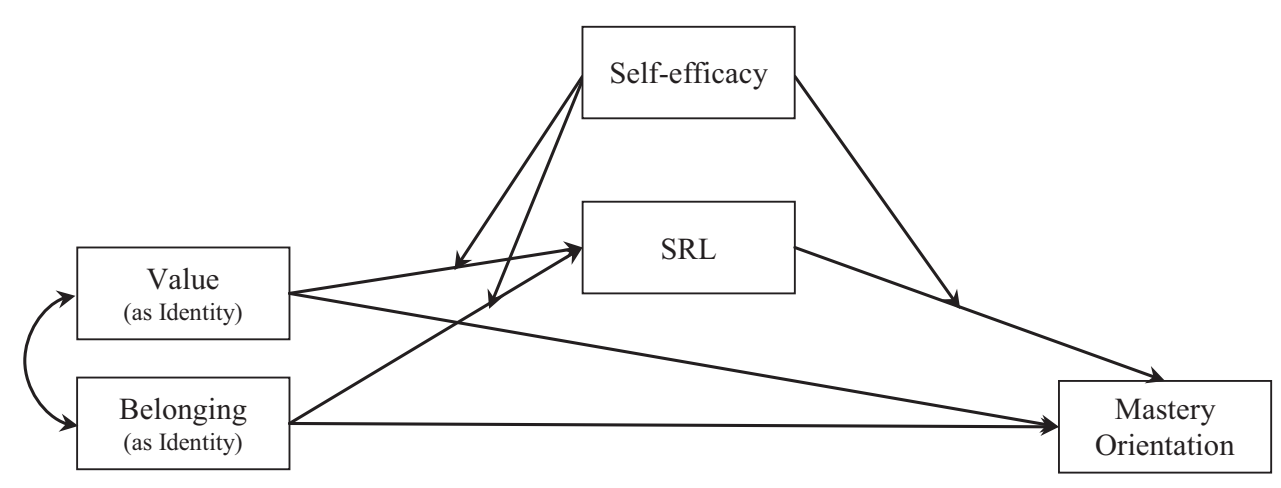

(b)

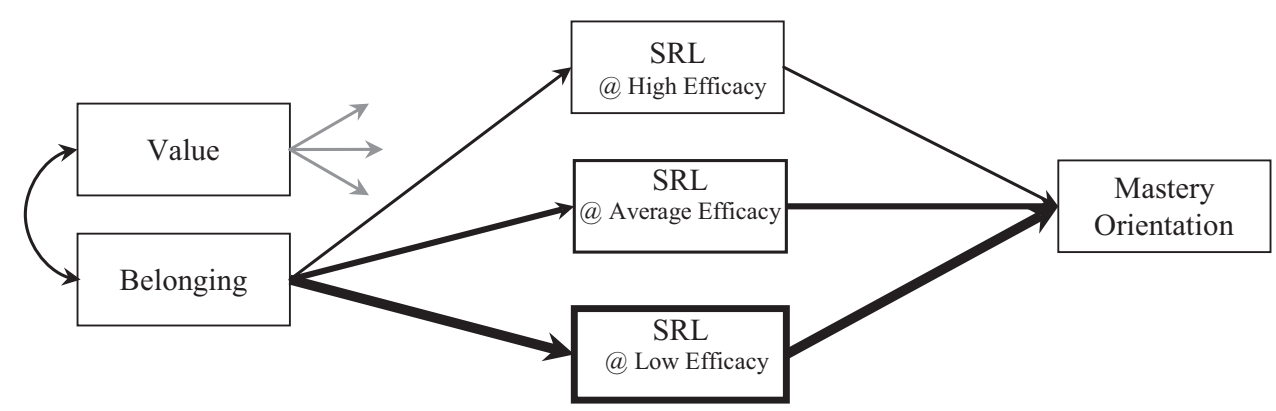

Figure 1. Conceptual model. (a) The conceptual pathways of mediation and moderated mediation that we examine in this study. (b) Our Hypotheses $2 \mathrm{a}$ and $2 \mathrm{~b}$ that self-regulated learning has a stronger mediating role between belonging and mastery for low efficacy students compared to those who have high efficacy. We do not propose a hypothesis for the direction of self-efficacy's moderation effect on value.

school education, $34 \%$ had a high school diploma or equivalent degree, $22 \%$ had a high school diploma and some additional schooling, 11\% had an associate degree, 6\% had a bachelor degree, and $2 \%$ had an advanced or professional degree. As shown in Table 1, students with available background information were less likely to be male $(r=-.117, p<.01)$, and reported somewhat lower value $(r=-.087, \quad p<.05)$ and belonging $(r=-.080, p<.05)$. No other differences emerged. Whether background information was provided by the participants' parents (yes vs. no) was utilized as a control variable in subsequent analyses. However, the relations of background information to value and belonging were not significant once the mediation and moderation models were tested. Therefore, this binary variable was removed from the list of control variables and is not discussed further. Gathered background information such as mother's education was retained as a control variable.

\section{Procedure}

Adolescents who participated in this study were recruited from their respective schools with the permission of administrators and teachers, as well as personal assent from each participant. Family background questionnaires were distributed with the parental consent forms. The response rate for consent was $73 \%$.

\section{Measures}

Value

The intrinsic value subscale from the adolescent version of the Motivated Strategies for Learning Questionnaire (MSLQ; Pintrich \& De Groot, 1990) was used. The MSLQ has been validated for populations ranging from fourth grade to the postcollegiate level. The intrinsic value subscale consisted of seven items concerning the perceived importance of course work (e.g., "It is important for me to learn what is 
Table 1

Correlation Matrix and Descriptive Statistics

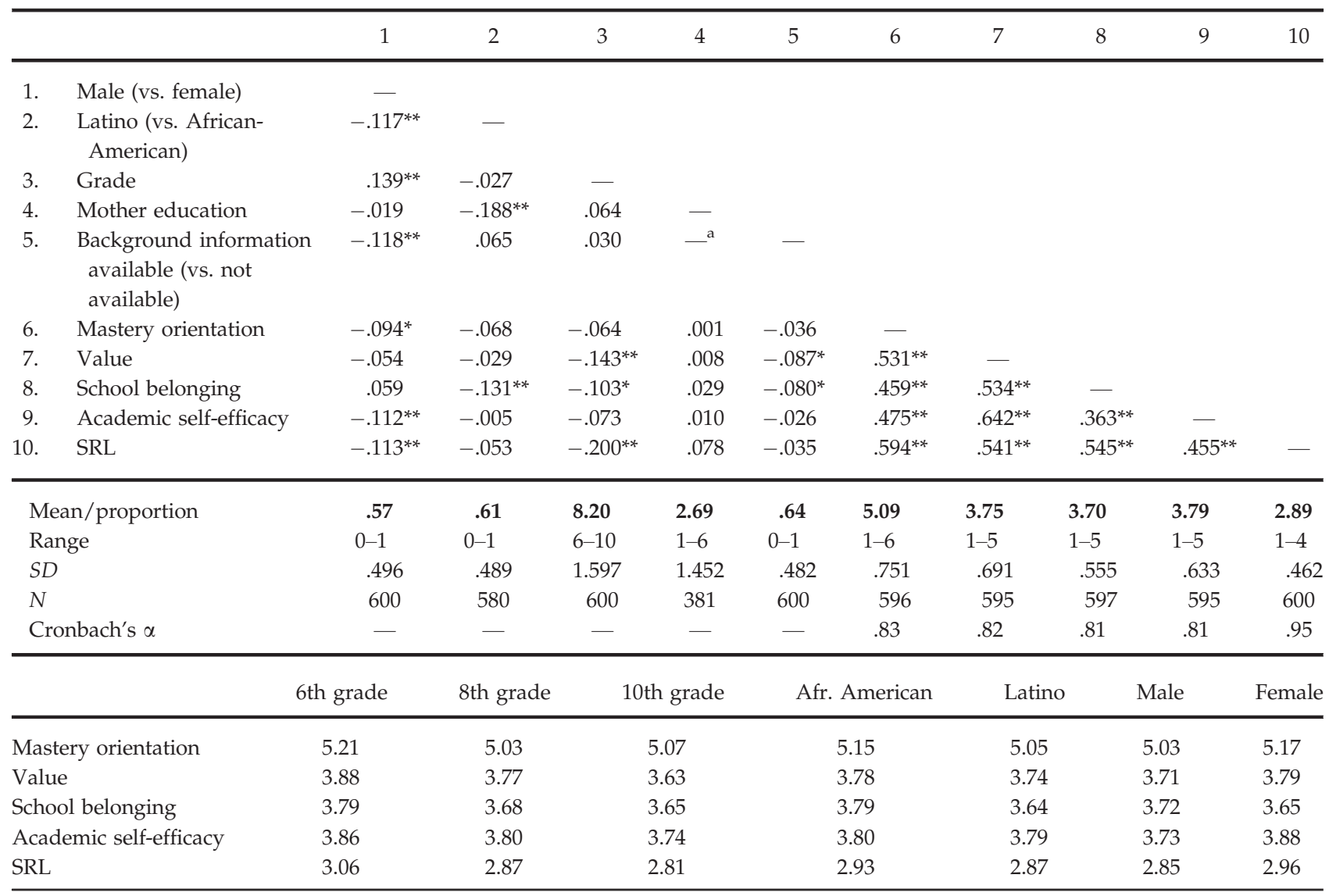

Note. SRL = self-regulated learning.

${ }^{a}$ Mother's education was available only for those students whose parents provided background information. Accordingly, the correlation coefficient is not meaningful.

$* p<.05 . * * p<.01$.

being taught in class"), intrinsic interest (e.g., "I think what we are learning in class is interesting"), and perceived utility (e.g., "I think that what I am learning in class is useful for me to know"). Thus, although the measure is entitled "intrinsic value," it captures the multiple components of achievement values as defined by Eccles and her colleagues (i.e., intrinsic, attainment, and utility values). Participants rated all scale items from 1 (strongly disagree) to 5 (strongly agree). The scale had satisfactory internal consistency $(\alpha=.82)$. This domain-level measure was used to assess the perceived importance, interest, and usefulness of engaging in academic activities across multiple academic subjects.

\section{Belonging}

Fifteen items in the Identification with School Questionnaire (ISQ; Voelkl, 1996) assess school belonging (e.g., "I feel proud of being part of my school," "People at school are interested in what I have to say") and an internalization of commitment to school ("School is one of the most important things in my life"). Participants rated all items on a scale from 1 (strongly disagree) to 5 (strongly agree). The original assessment contained 16 items; one item ("I can get a good job even if my grades are bad") was dropped due to its low loading on the construct in the present sample. This scale had good internal consistency $(\alpha=.81)$. The ISQ has been validated as a measure of emotional-affective attachment to one's school or school bonding (Voelkl, 1997).

\section{Academic Self-Efficacy}

The self-efficacy scale was also derived from the MSLQ and consists of seven items regarding perceived competence in performance of class work (e.g., "I am sure I can do an excellent job on the problems and tasks assigned for class"). Partici- 
pants rated all items on this scale from 1 (strongly disagree) to 5 (strongly agree). The scale had good internal consistency $(\alpha=.81)$. This measure captures a domain-level (e.g., general classwork), as opposed to a task-specific, conceptualization of selfefficacy (e.g., algebraic word problems). Although self-efficacy is often described as task specific, Schunk and Parajes (2004) note how task-specific self-efficacy develops over time into a general perception of academic self-efficacy.

\section{Self-Regulated Learning}

To assess SRL, we used Strategies for the Regulation of Academic Cognition, Motivation, and Behavior (Wolters, Pintrich, \& Karabenick, 2003), which is adapted from the MSLQ. Three subscales within this measure were cognitive, motivation, and behavioral regulation. The cognitive subscale contained 22 items measuring students' rehearsal, elaboration, organizational, and metacognitive strategies (e.g., "Whenever I read for class, I try to make a mental image of what is being discussed"). The motivation regulation subscale had 28 items measuring self-talk, interest enhancement, self-consequating, and environmental structuring (e.g., "I try to connect the material with something I like doing or find interesting"). The behavioral regulation subscale used four items to measure intention to seek help and persistence regulation (e.g., "Even when course materials are dull and uninteresting, I manage to keep working until I finish"). The scores of each subscale showed adequate internal consistency (cognitive $\alpha=.89$, motivation $\alpha=.93$, behavioral regulation $\alpha=.65$ ). A confirmatory factor analysis in which SRL was operationalized as a second-order factor had satisfactory model fit $\left(\chi^{2}=129.80, d f=32\right.$, comparative fit index $[\mathrm{CFI}]=.96$, Tucker-Lewis index $[\mathrm{TLI}]=.94$, root mean square error of approximation [RMSEA] $=.07$, $90 \%$ CI $[.06, .08]$, standardized root mean square residual $[$ SRMR] $=.03$ ). Here, cognitive, motivational, and behavioral strategies were modeled as first-order factors, and specific strategies (e.g., elaboration) as observed indicators. Thus, only one SRL score indicating students' tendency to regulate their learning using cognitive, motivational, and behavioral regulatory strategies was included in subsequent analyses. This overall factor had very good internal consistency $(\alpha=.95)$.

\section{Mastery Orientation}

The revised achievement goal orientation measure (Midgley et al., 1998) assessed achievement motivation as conceptualized by goal theory, which highlights the epistemological beliefs that direct motivation and learning. The mastery orientation scale comprised four items and measured the desire for mastery goals in the achievement setting (e.g., "One of my goals in class is to learn as much as I can"). Items were scaled from 1 (strongly disagree) to 6 (strongly agree). The scale had good internal consistency $(\alpha=.83)$.

\section{Control Variables}

Gender (male vs. female), ethnicity (African American vs. Latino American), grade level (6th, 8 th, or 10th grade), and mother's level of education $(1=$ less than high school degree to $6=$ graduate or professional degree) were included in the subsequent analyses as control variables.

\section{Data Analysis Plan}

Initially, correlational patterns and descriptive data were examined to assess the relation among the study variables as well as gender, ethnicity, grade level, and background differences (see Table 1). Due to the nested structure of the data, a fully unconditional multilevel model was run with mastery orientation as the dependent variable to assess the partition of variance at the student level and the school level. The classroom level was not a functional structure for these data, as secondary students rotate and separate among several different classes daily. The intraclass correlation coefficient revealed approximately $3 \%$ of the variance was explained between schools, negating the need for further multilevel analyses (Bryk \& Raudenbush, 1992).

The hypothesized mediation and moderated mediation were assessed with path analyses via Mplus (Muthén \& Muthén, 2010), using full information maximum likelihood estimation to account for missing data. The first research hypothesis modeled SRL as a mediator in the relation between both value and belonging and mastery orientation. Following Baron and Kenny (1986), we examined whether: (a) the independent variables and dependent variable are significantly related, (b) the independent variables and mediator were significantly related, and (c) the mediator and dependent variable were significantly related; (d) the relation between the independent variables and dependent variable becomes weaker (partial mediation) or nonsignificant (full mediation) when the mediator is added to the model. 
Second, to address moderated mediation (Preacher et al., 2007) with self-efficacy (moderator) and SRL (mediator) for the relation between identity and mastery, we assessed three additional conditions, assuming the existence of mediation as outlined above: (a) a significant identity by self-efficacy interaction effect on SRL, (b) a significant SRL by self-efficacy interaction effect on mastery, and (c) a possible variation in the indirect effects of academic identity (value and belonging) on mastery, via SRL, at different levels of self-efficacy. These analyses allow us to determine if the paths between identity and SRL, and between SRL and mastery change as a function of high versus low self-efficacy. Ethnicity, gender, grade level, and mother's level of education were included as control variables in all inferential analyses.

\section{Results}

Initial descriptive analyses (Table 1) indicated that males reported somewhat lower mastery orientation $(r=-.09)$, self-efficacy $(r=-.11)$, and self-regulation $(r=-.11)$ than females; Latino adolescents reported somewhat lower sense of school belonging relative to African American adolescents $(r=-.13)$; and adolescents in higher grades reported somewhat lower value $(r=-.14)$, belonging $(r=-.10)$, and self-regulation $(r=-.20)$, all $p$ s $<.05$.

As expected, significant positive correlations emerged between value and belonging $(r=.53$; see Table 1), self-efficacy and SRL $(r=.46)$, self-efficacy and mastery orientation $(r=.48)$, and SRL and mastery orientation $(r=.59$, all $p$ s $<.05)$. Thus, all conditions for the proposed mediation analyses were fulfilled. Furthermore, self-efficacy was positively related to intrinsic value $(r=.64)$ and school belonging $(r=.36)$, suggesting that students with a higher sense of self-efficacy valued school more and had a greater sense of belonging $(p<.05)$. The association between self-efficacy and value was substantially stronger compared to the relation between self-efficacy and belonging (about $41 \%$ vs. $13 \%$ shared variance, respectively).

\section{Mediation}

Mediation was tested via path analyses. The notation used for the paths in Figure 2 is referenced throughout the manuscript. The final mediation model is illustrated in Figure 3, and relevant coefficients are reported in Table 2. Following Preacher et al.'s (2007) recommendations, significance was determined using bias-corrected bootstrap confidence intervals with 5,000 iterations (see Table 2). Bootstrapping does not require any assumptions about the shape of the sampling distribution of estimated effects or about the standard errors. Therefore, it is preferable to normal-theory tests of mediation.

SRL partially mediated the relation between the two identity dimensions and mastery orientation. Specifically, value $\left(c_{1}=.40, p<.001\right)$ and belonging $\left(c_{2}=.25, p<.001\right)$ had a direct positive relation to mastery, accounting for $33 \%$ of its variance and confirming Hypothesis 1a. SRL was also positively related to mastery $(b=.40, p<.001$; Hypothesis $1 \mathrm{~b})$. Finally, allowing SRL to mediate value, belonging and mastery led to a decrease in these direct effects for both value $\left(c_{1}^{\prime}=.26\right)$ and belonging $\left(c^{\prime}{ }_{2}=.10\right)$. Both coefficients remained significant, however, suggesting partial mediation and satisfying Hypothesis 1c. Significant indirect effects confirmed that SRL functions as a mediator of the effects of value $\left(\theta_{1}=.14, p<.001\right)$ and belonging $\left(\theta_{2}=.14, p<.001\right)$ on mastery orientation. Overall, the three predictors explained $42 \%$ of the variance in mastery orientation. The estimated path coefficients suggest that $1 S D$ increase in value corresponds to $.14 S D$ increase in mastery through the mediating effect of SRL, and $.26 S D$ increase in mastery through the direct (nonmediated) effect of value. Analogously, 1 SD increase in belonging corresponds to $.14 S D$ increase in mastery orientation through the mediation of SRL, and $.10 S D$ increase through the direct (nonmediated) effect of belonging. Including gender, ethnicity, grade level, and mother's education as control variables did not change the results and contributed only $1 \%$ and $2.8 \%$ additional explained variance in mastery and SRL, respectively. Accordingly, these variables were not retained in our final model presented in Figure 3.

The model presented in Figure 3 is just identified (i.e., the number of estimated parameters equals the available degrees of freedom); therefore, it is not possible to evaluate model fit. However, since the estimated path coefficients between value and SRL, and between belonging and SRL were approximately the same (.35 and .36, respectively), we were able to impose an equivalence constraint and thus estimate just one coefficient for both paths. This constraint reduced the number of estimated parameters by one and allowed us to confirm that the model fit the data very well $\left(\chi^{2}=1.69\right.$, $d f=1, \quad$ CFI $=.99, \quad$ TLI $=.99, \quad$ RMSEA $=.03$, SRMR $=.01$ ). Using this model as a baseline, we further tested the assumption of full versus partial mediation by fixing the direct paths between value and mastery, and belonging and mastery to zero. In 
(a)

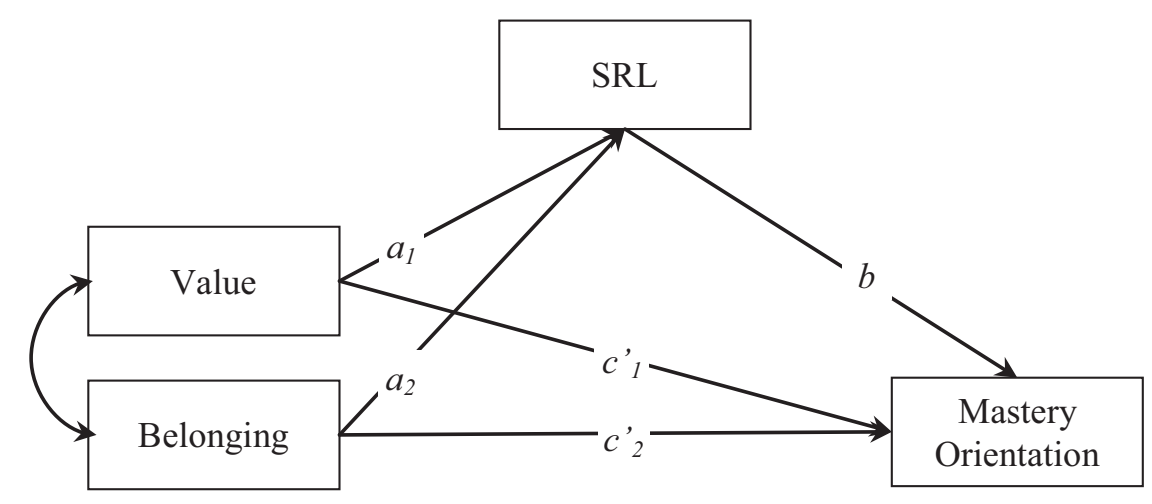

(b)

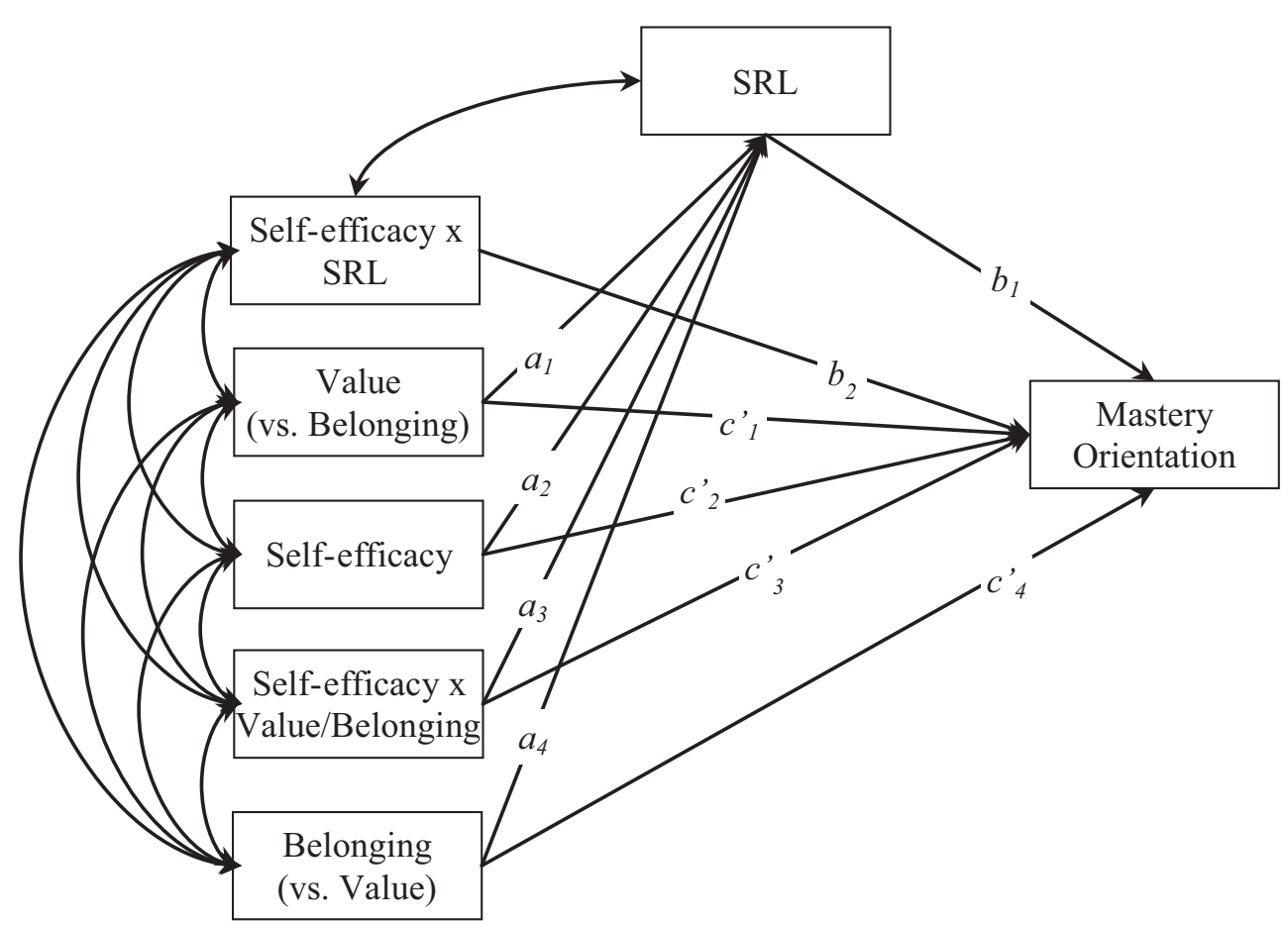

Figure 2. Analytical model for hypothesized mediation (a) and moderated mediation (b), following procedures described by Preacher, Rucker, and Hayes (2007). Residual variances for self-regulated learning and mastery orientation were estimated but are not included in the figure for simplicity. Amount of explained variance is reported in the analyses. When value was modeled as an independent variable, school belonging functioned as a control variable, and vice versa.

both cases, the zero constraints led to a significant decrease in model fit $(p<.01)$, providing further support for partial as opposed to full mediation.

\section{Moderated Mediation}

With SRL established as a mediator, the second hypothesis tested moderated mediation, which examined whether the mediation pattern described in the previous section varies as a function of having high versus low self-efficacy. Analogous to work by Preacher et al. (2007, Model 5), the path analysis consisted of the two identity dimensions (value and belonging) as independent variables, SRL as a mediator, self-efficacy as a moderator of both mediation paths ( $a$ and $b$ ), and mastery as the 


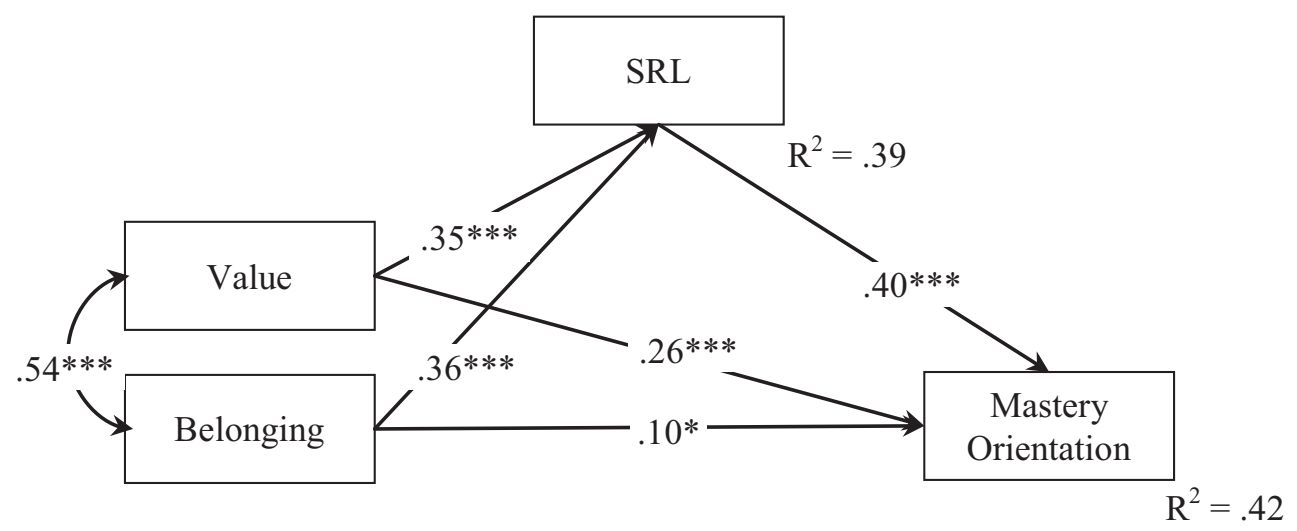

Figure 3. Mediation analysis. Standardized coefficients shown. Confidence intervals and standard errors were determined via bias-corrected bootstrap with 5,000 iterations. SRL $=$ self-regulated learning. $* p<.05 . * * * p<.001$.

Table 2

Mediation Analyses

\begin{tabular}{|c|c|c|c|}
\hline Tested effects & $\begin{array}{l}\text { Unstandardized } \\
\text { coefficient }\end{array}$ & $\begin{array}{c}95 \% \text { bias-corrected } \\
\text { bootstrap CI }\end{array}$ & $\begin{array}{c}\text { Standardized } \\
\text { coefficient }\end{array}$ \\
\hline \multicolumn{4}{|l|}{ Direct effects without mediator } \\
\hline Value $\rightarrow$ Mastery $\left(c_{1}\right)$ & .435 & {$[.328, .542]$} & $.400^{* * *}$ \\
\hline Belonging $\rightarrow$ Mastery $\left(c_{2}\right)$ & .333 & {$[.200, .461]$} & $.246^{* * *}$ \\
\hline \multicolumn{4}{|l|}{ Direct effects with mediator } \\
\hline Value $\rightarrow$ SRL $\left(a_{1}\right)$ & .233 & {$[.179, .288]$} & $.349^{* * *}$ \\
\hline Belonging $\rightarrow$ SRL $\left(a_{2}\right)$ & .299 & {$[.233, .364]$} & $.360^{* * *}$ \\
\hline Value $\rightarrow$ Mastery $\left(c_{1}^{\prime}\right)$ & .285 & {$[.180, .385]$} & $.263^{* * *}$ \\
\hline Belonging $\rightarrow$ Mastery $\left(c_{2}^{\prime}\right)$ & .139 & {$[.016, .262]$} & $.103^{*}$ \\
\hline SRL $\rightarrow$ Mastery $(b)$ & .644 & {$[.510, .781]$} & $.396^{* * *}$ \\
\hline \multicolumn{4}{|l|}{ Indirect effects } \\
\hline $\begin{array}{l}\text { Value } \rightarrow \text { SRL } \rightarrow \text { Mastery (controlling } \\
\text { for belonging) }\end{array}$ & .150 & {$[.107, .201]$} & $.138^{* * *}$ \\
\hline $\begin{array}{l}\text { Belonging } \rightarrow \text { SRL } \rightarrow \text { Mastery (controlling } \\
\text { for value) }\end{array}$ & .192 & {$[.139, .259]$} & $.142^{* * *}$ \\
\hline
\end{tabular}

Note. Amount of explained variance in mediation model for mastery orientation $R^{2}=.42$ and for SRL $R^{2}=.39$. SRL $=$ self-regulated learning.

$* p<.05 . * * * p<.001$.

dependent construct. When value was modeled as the independent variable, belonging was considered a control variable (Model $\mathrm{A}$ in Table 3 and Figure 4), and vice versa when belonging was modeled as the independent variable (Model B in Table 3 and Figure 4). Thus, only variance that is unique for each of these constructs was examined. Standard errors were derived from a bias-corrected bootstrap sampling distribution with 5,000 iterations, and the significance of modeled effects was evaluated using bias-corrected bootstrap confidence intervals. All predictors were mean-centered so that estimated path coefficients indicate effects at average self-efficacy. For significant interaction effects between self-efficacy and SRL, value, or belonging, the direct and indirect effects in Figure 4 and Table 3 were also examined at high ( $1 S D$ above the mean) and low (1 SD below the mean) self-efficacy.

Overall, the analyses indicate that self-efficacy was a significant moderator for belonging, but not value, although some marginally significant effects emerged for value. These findings support our second Hypothesis (2a) for belonging, but not for 
Table 3

Moderated Mediation Analyses for Value (Model A) and Belonging (Model B) as Independent Variables

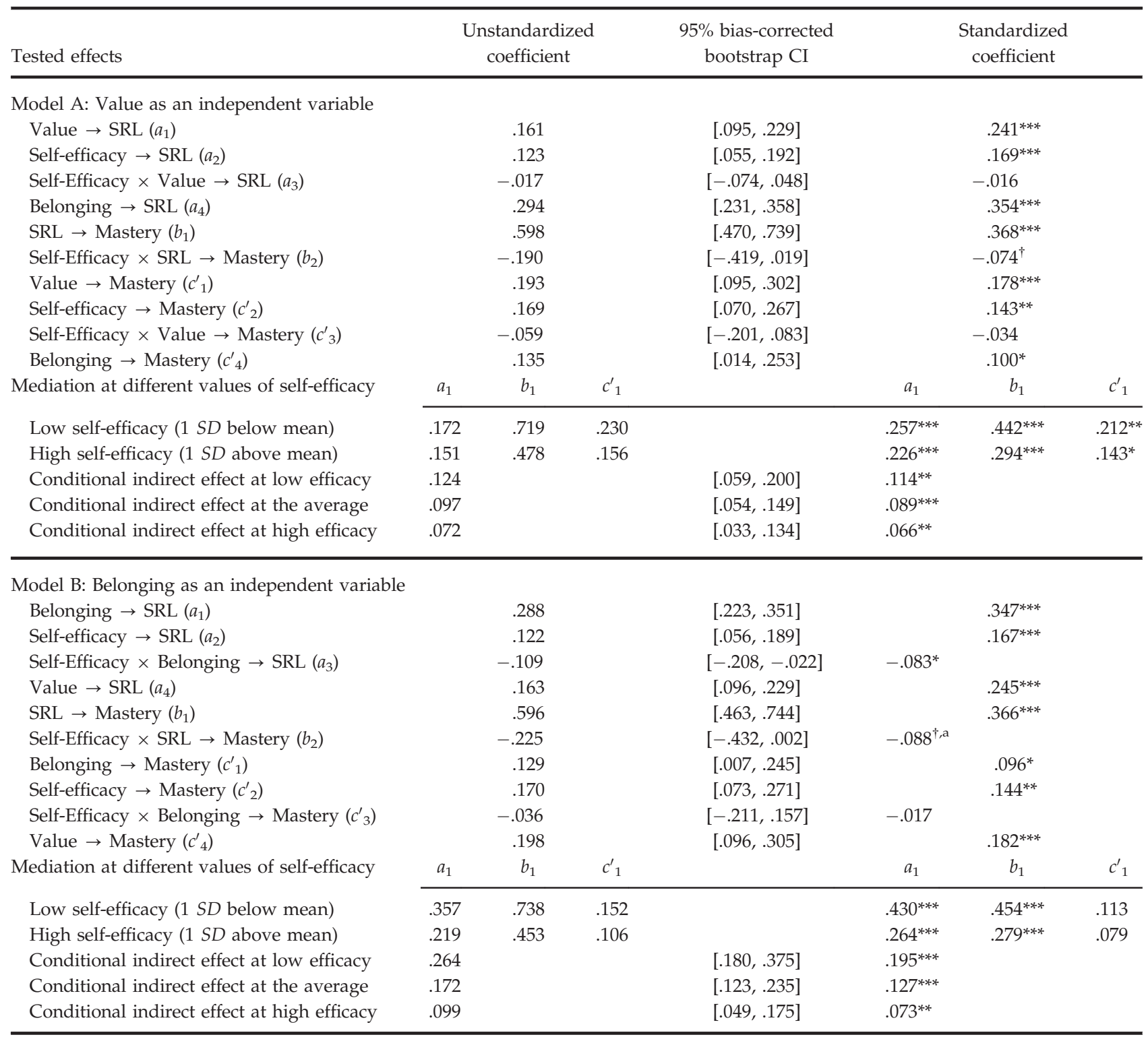

Note. Tested models are illustrated in Figure 2. In Model A: Mastery $R^{2}=.45$, SRL $R^{2}=.40$; in Model B: Mastery $R^{2}=.45$, SRL $R^{2}=.41$. Note that there is only marginal moderation effect in Model A for Self-Efficacy $\times$ SRL (moderation of path $b$ ). Mediation at different values of self-efficacy for this marginal effect in Model A is reported for completeness. SRL = self-regulated learning.

${ }^{a} p=.044$; however, the $95 \%$ confidence interval includes the zero point, and the coefficient became only marginally significant at $p=.054$ after including gender, ethnicity, grade level, and mother's education as control variables.

${ }^{\dagger} p<.10 . * p<.05 . * * p<.01 . * * * p<.001$.

value. Specifically, the interaction between self-efficacy and value had no significant effects on SRL $\left(a_{3}=-.02, n s\right)$ or mastery orientation $\left(c^{\prime}{ }_{3}=-.03\right.$, $n s)$, which suggests that despite being positively related to each of these constructs, self-efficacy did not function as a moderator (see Model A in Table 3 and Figure 4). The interaction between selfefficacy and SRL was only marginally significant for mastery $\left(b_{2}=-.07, p=.089\right)$, which does not provide adequate support for Hypothesis $2 b$. Thus, no evidence was found that self-efficacy functions as a moderator of the identified mediation when identity is defined as value.

Because of the marginally significant interaction between self-efficacy and SRL $\left(b_{2}=-.07, p=.089\right)$, and for the sake of completeness, we examined 
Model A

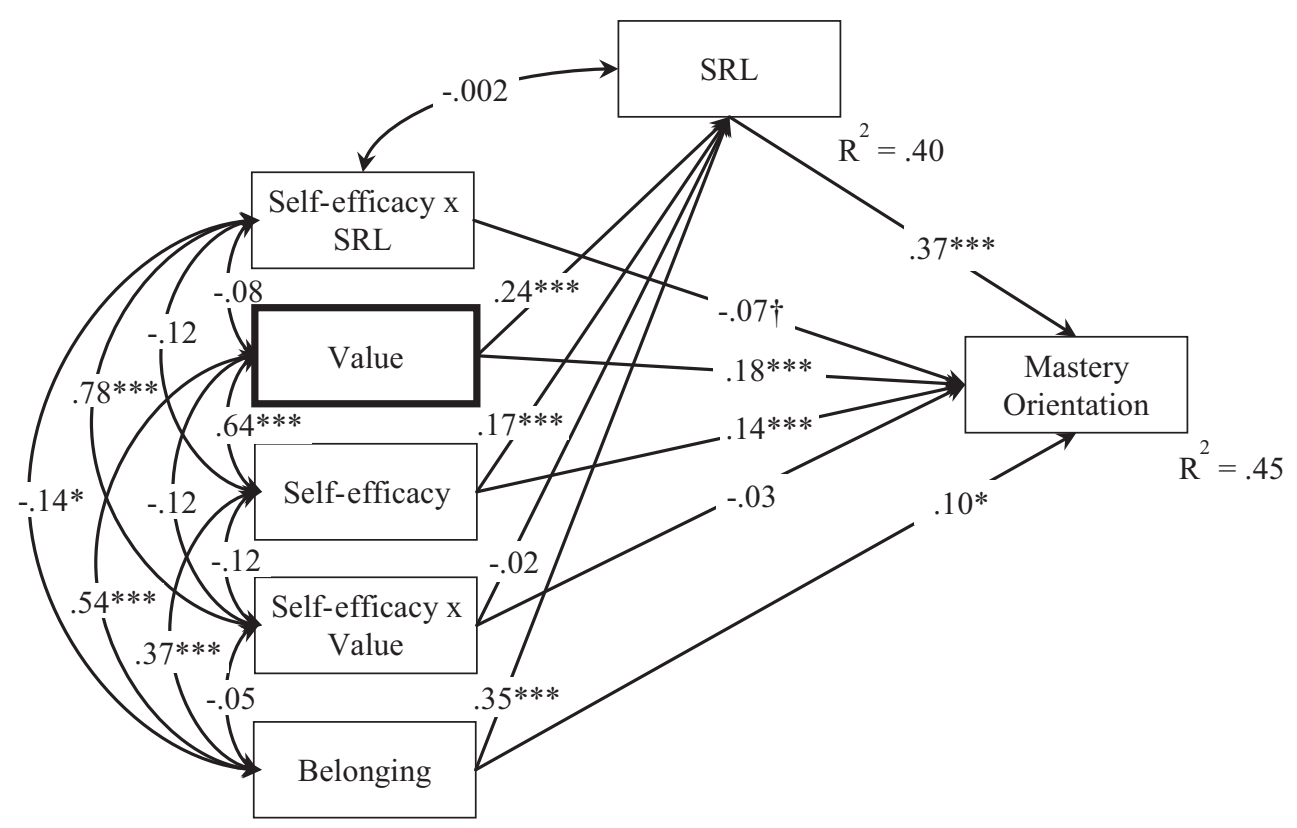

Model B

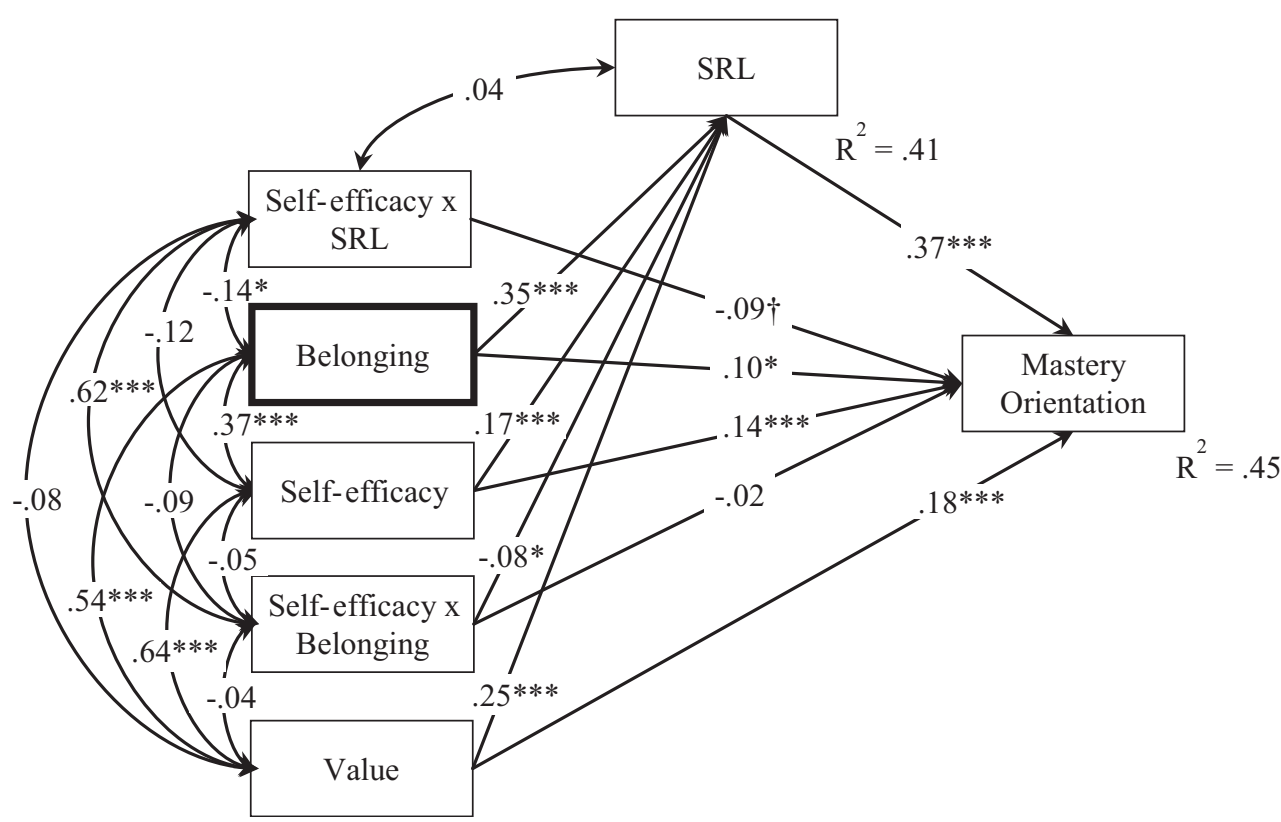

Figure 4. Moderated mediation with value (Model A) and belonging (Model B) as independent (vs. control) variables, self-regulated learning (SRL) as a mediator, self-efficacy as a moderator, and mastery orientation as a dependent variable. Residual variances for SRL and mastery orientation were estimated but are not included in the figure. Amount of explained variance is reported instead. Standardized coefficients are reported.

${ }^{\dagger} p<.10 . * p<.05 . * * * p<.001$.

whether the indirect effect of value on mastery via SRL, and the direct paths between value, SRL, and mastery (paths $a_{1}, b_{1}$, and $c^{\prime}{ }_{1}$ in Figure 2 , and in Table 3) vary at different levels of self-efficacy.
Conditional indirect and direct effects were computed for low (1 SD below the mean), average, and high (1 SD above the mean) self-efficacy. The conditional indirect effect for our model is computed as, 


$$
f(\hat{\theta} \mid S E)=\left(\hat{a}_{1}+\hat{a}_{3} S E\right)+\left(\hat{b}_{1}+\hat{b}_{2} S E\right)
$$

where SE is a value representing high, average, or low self-efficacy, and the $a$ and $b$ coefficients correspond to the ones illustrated in Figure 2b (see also Preacher et al., 2007, p. 198).

As shown in Table 3, Model A, the mediated effects of value on mastery were significant at all three levels of self-efficacy. The estimated coefficients suggest that for students with low, average, and high self-efficacy, respectively, $1 S D$ increase in value corresponds to .11, .09, and .07 SD increase in mastery, mediated through SRL, and $.21, .18$, and $.14 S D$ (see $c^{\prime}$, Model A in Table 3) increase in mastery through the direct (nonmediated) effect of value (and controlling for SRL). Thus, the direct and indirect effects of value on mastery were somewhat larger at lower levels of self-efficacy; however, the absence of significant interaction effects suggests self-efficacy does not function as a significant moderator in this model. Overall, Model A (value as independent variable) explained $45 \%$ of the variance in mastery and $40 \%$ of the variance in SRL. Gender, ethnicity, grade level, and mother's education did not affect the results and contributed only $0.8 \%$ and $2.6 \%$ additional explained variance in mastery and SRL, respectively. Therefore, these variables were not retained in the final model illustrated in Figure 4.

In the model with belonging as the independent variable (Model B in Table 3 and Figure 4), self-efficacy emerged as a significant moderator of the path between belonging and SRL $\left(a_{3}=-.08, p<.05\right)$, was not a significant moderator of the direct effect of belonging on mastery $\left(c^{\prime}{ }_{3}=-.02, n s\right)$, and was a marginally significant moderator of the link between SRL and mastery $\left(b_{2}=-.08, p=.054\right)$. We proceeded with testing conditional indirect effects at low (1 SD below the mean), average, and high (1 SD above the mean) levels of self-efficacy. The estimated coefficients shown in Table 3, Model B, and illustrated in Figure 4, suggest that for students with low, average, and high self-efficacy, respectively, $1 S D$ increase in belonging corresponds to $.20, .13$, and $.07 S D$ increase in mastery, mediated through SRL, and .11, .10, and .08 SD (see $c^{\prime}{ }_{1}$, Model B in Table 3) increase in mastery through the direct (nonmediated) effect of belonging. These estimates suggest that both the mediated and nonmediated effects of belonging on mastery are strongest for students with low self-efficacy. Controlling for SRL, the direct path between belonging and mastery was relatively small and reached significance only for average self-efficacy $\left(c^{\prime}{ }_{1}=.10\right.$, $p<.05)$, but not for high or low levels of self-efficacy $\left(c_{1}^{\prime}=.08\right.$ and .11 , respectively). This model thus suggests that belonging is less likely to be related to mastery directly, but rather indirectly through its positive association with SRL, especially for students with a low sense of academic self-efficacy.

Overall, the variables in Model B (belonging as independent variable) explained $45 \%$ of the variance in mastery, and $41 \%$ of the variance in SRL. Gender, ethnicity, grade level, and mother's education were included as control variables, but did not affect the results and contributed only $0.7 \%$ and $2.7 \%$ additional explained variance in mastery and SRL, respectively. Similar to the previous analyses, they were not retained in our final model illustrated in Figure 4.

Similar to the mediation model, the moderated mediation analyses in Model A and Model B were just identified and did not allow assessments of model fit. However, fixing the nonsignificant path coefficients to zero across both models reduced the number of estimated parameters and allowed tests of fit to the data. The fit was very good in both models (path $c^{\prime}{ }_{3}$ was fixed to zero in both models, Model A: $\chi^{2}=1.08, d f=1$, CFI $=1.00$, TLI $=.99$, RMSEA $=.01, \quad$ SRMR $<.01$; Model B: $\chi^{2}=0.25$, $d f=1, \quad$ CFI $=1.00, \quad$ TLI $=1.00, \quad$ RMSEA $<.01$, SRMR < .01).

\section{Discussion}

The current study examines the motivational significance of two dimensions of emergent identity (value and belonging) within a sample of African American and Latino adolescents. A study of this scope is important as much of the research literature on academic identity development among African American and Latino youth operationalize identity as one dimension. Furthermore, the processes that translate identity into motivated engagement have not received sufficient attention, particularly within these populations. The present findings begin to address these limitations in a few important ways.

First, the mediation results suggest that SRL may be one essential pathway by which academic identity predicts achievement motivation. Adolescents who are highly identified with academics are more likely to enact the cognitive, volitional, and behavioral strategies that also scaffold their 
mastery orientation (see also Paris \& Paris, 2001). Traditionally, SRL studies have demonstrated that students are likely to regulate their learning as a result of specific learning goals or tasks (Pintrich, 2000); however, an identity-based approach to motivation is important to acknowledge as well. Here, adolescents are willing to enact strategic and effortful behaviors that validate how they see themselves. As they do so, this effortful engagement seems to also scaffold their mastery learning orientation.

This study also advances the achievement literature on African American and Latino adolescents by coalescing two key concepts into one integrated framework. These data illustrate value and belonging as distinct but cohabitating dimensions of academic identity (Ashmore et al., 2004; Osborne \& Jones, 2011). While both dimensions have meaningful implications for achievement motivation (Eccles, 2009; Faircloth, 2012), our findings indicate that their effects are partially mediated through their links to SRL. Thus, identity seems to be important for mastery in a way that supports active participation and effortful engagement among African American and Latino adolescents.

The results add further nuance. Identification may not relate to SRL and mastery equally across all students. The willingness to engage in effortful self-regulated behaviors differs across internal (i.e., value) versus external (i.e., belonging) perceptions of identity and is moderated by academic self-efficacy, supporting our second hypothesis. Conditional indirect effects for low, average, and high levels of self-efficacy demonstrate that SRL holds differential weight as a mediator for students with different levels of academic self-efficacy, specifically for the relation between belonging and mastery. For low-efficacy students, SRL mediates belonging and mastery, whereas for high-efficacy students belonging is a weaker predictor of mastery via SRL.

Altogether, the mediation model may recommend the importance of assessing both value and belonging collectively (Finn, 1989) for a comprehensive framework for understanding motivation in African American and Latino adolescents. However, the moderated mediation models illustrate not only how identity is related to mastery, but for whom this process is most meaningful. For students with low academic self-efficacy, the externally focused perceptions of school belonging are quite essential for predicting mastery through SRL (Honora, 2003; Nasir et al., 2011). Value is still related to mastery for low-efficacy students; how- ever, these data suggest less so through the pathway of SRL, relative to its direct effects. On the other hand, feelings of belonging may be a distinctive form of encouragement for struggling students, specifically, scaffolding effort and motivation. Although belonging is important for motivation generally, students who are marginalized may lack confidence in their academic capabilities, thereby drawing upon the relational resources of the school community may be particularly beneficial for their self-regulatory skills. School personnel could support such relational resources, for instance, through strong teacher-student relationships, positive peer support, ideational and emotional encouragement, or extracurricular events (e.g., programs, clubs, and teams). This may help these students garner support for regulated learning behaviors and consequently mastery (Faircloth, 2009; Nasir \& Cooks, 2009), even when they lack self-efficacy.

The implications of these findings have relevance for historically marginalized adolescents for whom perpetual feelings of alienation and disconnectedness within schools (Thomas \& Stevenson, 2009) can be uniquely caustic for motivation and in turn academic performance (Honora, 2003; Singh et al., 2010). This study corroborates claims that marginalized adolescents who struggle to achieve well can still become motivated and self-regulated in academic contexts if they perceive themselves as integrated and appreciated members of the academic community (Honora, 2003; Nasir et al., 2011). Whereas external sources of academic identity-a sense of school belonging-had only weak associations with self-regulation and motivation for highefficacy students, this relation was stronger for struggling students, who may rely more on the emotional-affective support of people and resources within their school community. Ultimately, this work challenges the literature that solely focuses on value and contributes to a growing body of research that advances belonging as an area where adults can support adolescent development with youth who often face academic challenges.

\section{The Emergence of "Belonging" in Research on Adolescent Development in Urban Schools}

Given the present findings, it is imperative to consider the significance of belonging during adolescence as a fundamental developmental issue. To date, there has been ample research on the importance of school belonging broadly (Anderman \& Freeman, 2004; Goodenow \& Grady, 1993; Juvonen, 2006). However, the acute relevance of belonging 
for historically marginalized populations is still emerging (Faircloth \& Hamm, 2005; Nasir et al., 2011; Sanchez et al., 2005; Walton \& Cohen, 2011). The current study is well positioned within this growing literature, illustrating that belonging among African American and Latino adolescents in urban schools is not only an essential motivational construct, but a unique scaffold for struggling adolescents in particular, keeping them effortful academically and buffering against disengagement despite feelings of low efficacy.

Doubts about academic abilities or declining efficacy are quite normal during early adolescence, which may stem from increased academic rigor in middle school as well as stage-environment misfit (see Eccles \& Roeser, 2011). However, African American and Latino adolescents are also learning to navigate unique social and cultural tensions that can further challenge feelings of efficacy. For example, urban schools that serve these populations tend to have more teachers with low expectations for students, higher negative affect and frustration surrounding instructional interactions, and greater cultural misconceptions and biases (Baker, 1999; Lynn et al., 2010). The newly emerging capacity for adolescent recursive thinking and social perspective taking now allow marginalized youth to be able to perceive these biases that their teachers hold against them. In addition, urban adolescents can begin to interpret the deeper social messages behind issues such as unsafe or ill-maintained school conditions, or outdated learning resources. These adolescents must also begin to manage broader societal messages regarding cultural stereotypes and negotiate what this means for their personal academic lives.

By the first 2 years of high school, these academic, social, and cultural pressures may have begun to take a toll on marginalized adolescents' efficacy beliefs. Moreover, in the 9th-10th grades, the stakes for achievement become dire and performance feedback more threatening, ultimately resulting in a dropout epidemic in urban schools among African American and Latino adolescents (Roderick, 2003; Stearns \& Glennie, 2006). Although value of education is important throughout this process, one can also understand how value alone may not support persistent academic effort in the face of declining efficacy and increasing academic pressures.

However, intentionally affirming urban minority adolescents as valued members of the school community, making them feel cared for, and giving them open access to articulate their social and academic difficulties is a critical opportunity for inter- vention, particularly for adolescents who may be struggling academically, as the this study would suggest. Teachers can offer opportunities for adolescents to engage in identity construction through both relational resources (e.g., interpersonal connections) and ideational resources (e.g., negotiated ideas about oneself and one's place in the world; Faircloth, 2009; Goodenow \& Grady, 1993; Honora, 2003; Nasir \& Cooks, 2009). For example, one study demonstrated an increase in feelings of school belonging among urban ninth graders when teachers utilized scaffolding in their lessons in ways that encouraged students to make connections between their culture, personal identity, and the literary themes of the texts they read in a ninth-grade English course, (e.g., Romeo \& Juliet, The Odyssey; Faircloth, 2009). Thus, students were encouraged to write and discuss their own identity issues, while relating it to themes of identity within the texts for the course. This is significant because adolescent changes in social cognition naturally make discussions around identity and interpersonal connections a topic of interest. Other work shows that not framing academic adversity and challenges as an indictment against one's belonging, but as natural to the school adjustment process, can be effective for African American adolescents (Walton \& Cohen, 2011). Also, it is unclear whether a strong connection with one's ethnic group has been associated with school belonging specifically; however, it has been shown to buffer the negative effects of school-based racial discrimination (Smalls et al., 2007; Wong et al., 2003).

Although most studies on belonging cannot determine directionality in the input-output process, some theorize that through school belonging, the school's ideation of values can become internalized over time, ultimately manifesting as the values of the individual (Finn, 1989; Voelkl, 1997). Hence, these two dimensions of identity may represent different phases along a developmental continuum of identity formation. From this we may conjecture that low-efficacy adolescents may initially rely on belongingness to support SRL and mastery until efficacy increases. At such a point, these once lowefficacy students may begin to develop more personal value for the content due to their increasing successes eventually relying less on belongingness support, which reflects the tendencies of higher efficacy students in these data specifically. The present study provides the foundation for answering this question in future research.

Gender differences and age-related changes are two important covariates that have been discussed 
broadly regarding achievement and adolescent transitions into secondary school. In the present data, controlling for gender did not influence observed relations between the study variables. This is consistent with prior research; for instance, Sanchez et al. (2005) also found that the effects of belonging on various motivational outcomes did not vary by gender. Our results were also robust after controlling for age differences (i.e., grade level), even though the data corroborate developmental declines (Eccles \& Roeser, 2011; Wigfield \& Eccles, 2002) across academic self-perceptions for older adolescents compared to early adolescents. This suggests that the relations examined in our analyses are applicable throughout early and middle adolescence.

A few important limitations should be addressed. First, mediation models often imply causality between independent and dependent constructs. However, our cross-sectional design does not allow us to substantiate the temporality of the variables in the order we propose. Thus, we describe our models in terms of relationships and prediction but do not assume causality. However, it is also important to note that for the constructs assessed in this study, even a longitudinal design would not be completely convincing of the temporal order of the variables due to the reciprocal nature of these relationships and that many of these constructs exist prior to sixth grade. Theory (Bandura, 2001; Paris \& Paris, 2001) has aided us in the construction of our models, presaging SRL as a mechanism for understanding the relation between sociostructural perceptions and one's learning orientation, as well as self-efficacy as an enabler of SRL.

Second, academic identity is often studied at the domain level, which we ascribe to in this article. However, notions of value, self-efficacy, and SRL have been shown to have task specificity (Wigfield \& Eccles, 2000). Future work should consider examining the multiple dimensions of identity for specific subject areas (e.g., math, science), as these constructs may show informative variability across academic subjects. Last, given that the data were collected via survey self-report, social desirability concerns must be considered. However, it is important to note that a construct such as identity is abstract and internally negotiated according to the perceptions of the individual. Hence, perceptions of identity are difficult to operationalize for an objective assessment, and thus psychologists have traditionally relied on self-report measures when measuring identity.

While the link between academic identity and motivation has been broadly discussed in theory, continued empirical research is needed to explicate such a link. Adolescents are multifaceted and complex; thus, our study of identity and motivation should mirror this complexity when possible. Here, we demonstrate how considering SRL and academic self-efficacy within a multidimensional conceptualization of academic identity adds informative complexity toward understanding the psychological processes of marginalized youth.

\section{References}

Anderman, E. M. (2002). School effects on psychological outcomes during adolescence. Journal of Educational Psychology, 94, 795-809. doi:10.1037/0022-0663.94.4.795

Anderman, L. H. (2003). Academic and social perceptions as predictors of change in middle school students' sense of school belonging. Journal of Experimental Education, 72, 5-22. doi:10.1080/00220970309600877

Anderman, L. H., \& Freeman, T. M. (2004). Students' sense of belonging in school. In M. Maehr \& P. Pintrich (Eds.), Advances in motivation and achievement: Vol. 13. Motivating students, improving schools: The legacy of Carol Midgley (pp. 27-63). Oxford, UK: Elsevier, JAI.

Ashmore, R. D., Deaux, K., \& McLaughlin-Volpe, T. (2004). An organizing framework for collective identity: Articulation and significance of multidimensionality. Psychological Bulletin, 130, 80-114. doi:10.1037/ 0033-2909.130.1.80

Baker, J. A. (1999). Teacher-student interaction in urban at risk classrooms: Differential behavior, relationship quality, and student satisfaction with school. Elementary School Journal, 100, 57-70.

Bandura, A. (2001). Social cognitive theory: An agentic perspective. Annual Review of Psychology, 52, 1-26. doi:10.1146/annurev.psych.52.1.1

Bandura, A., Barbaranelli, C., Caprara, G. V., \& Pastorelli, C. (1996). Multifaceted impact of self-efficacy beliefs on academic functioning. Child Development, 67, 1206-1222. doi:10.2307/1131888

Barber, B., Eccles, J., \& Stone, M. R. (2001). Whatever happened to the Jock, the Brain and the Princess? Young adult pathways linked to adolescent activity involvement and social identity. Journal of Adolescent Research, 16, 429-455.

Baron, R. M., \& Kenny, D. A. (1986). The moderatormediator variable distinction in social psychological research: Conceptual, strategic, and statistical considerations. Journal of Personality and Social Psychology, 51, 1173-1182. doi:10.1037/0022-3514.51.6.1173

Blumer, H. (1969). Symbolic interactionism: Perspective and method. Berkeley: University of California Press.

Bryk, A. S., \& Raudenbush, S. W. (1992). Hierarchical linear models. Newbury Park, CA: Sage.

Caprara, G. V., Fida, R., Vecchione, M., Del Bove, G., Vecchio, G. M., Barbaranelli, C., \& Bandura, A. (2008). Longitudinal analysis of the role of perceived self-efficacy for 
self-regulated learning in academic continuance and achievement. Journal of Educational Psychology, 100, 525.

Eccles, J. (2009). Who am I and what am I going to do with my life? Personal and collective identities as motivators of action. Educational Psychologist, 44, 78-89. doi:10.1080/00461520902832368

Eccles, J. S., \& Roeser, R. W. (2011). Schools as developmental contexts during adolescence. Journal of Research on Adolescence, 21, 225-241. doi:10.1111/j.1532-7795. 2010.00725.x

Erikson, E. H. (1968). Identity: Youth and crisis. New York, NY: Norton.

Faircloth, B. S. (2009). Making the most of adolescence: Harnessing the search for identity to understand classroom belonging. Journal of Adolescent Research, 24, 321.

Faircloth, B. S. (2012). "Wearing a mask" vs. connecting identity with learning. Contemporary Educational Psychology, 37, 186-194. doi:10.1016/j.cedpsych.2011.12.003

Faircloth, B. S., \& Hamm, J. (2005). Sense of belonging among high school students represent 4 ethnic groups. Journal of Youth and Adolescence, 34, 293-309.

Finn, J. D. (1989). Withdrawing from school. Review of Educational Research, 59, 117-142.

Goodenow, C., \& Grady, K. (1993). The relationship of school belonging and friends' values to academic motivation among urban adolescent students. Journal of Experimental Education, 62, 60-71.

Griffin, B. W. (2002). Academic disidentification, race, and high school dropouts. The High School Journal, 85, 71-81.

Harris, A. L. (2006). I (don't) hate school: Revisiting oppositional culture theory to Blacks' resistance in schooling. Social Forces, 85, 797. doi:10.1353/sof.2007.0006

Harter, S. (2006). The development of self-representations in childhood and adolescence. In W. Damon \& R. Lerner (Eds.), Handbook of child psychology (6th ed.). New York, NY: Wiley.

Honora, D. (2003). Urban African American adolescents and school identification. Urban Education, 38, 58-76. doi:10.1177/0042085902238686

Juvonen, J. (2006). Sense of belonging, social bonds, \& school functioning. In P. Alexander \& P. Winne (Eds.), Handbook of educational psychology (2nd ed., pp. 655674). Mahwah, NJ: Erlbaum.

Kaplan, A., \& Flum, H. (2012). Identity formation in educational settings: A critical focus for education in the 21st century. Contemporary Educational Psychology, 37, 171-175. doi:10.1016/j.cedpsych.2012.01.005

Lerner, R., Lerner, J., Almerigi, J., Theokas, C., Phelps, E., Gestsdottir, S., \& von Eye, A. (2005). Positive youth development, participation in neighborhood development programs, and neighborhood contributions of fifth-grade adolescents: Findings from the first wave of the 4-H study of positive youth development. Journal of Early Adolescence, 25, 17-71.

Luna, B., Padmanabhan, A., \& O'Hearn, K. (2010). What has fMRI told us about the development of cognitive control through adolescence? Brain and Cognition, 72, 101-113.
Lynn, M., Bacon, J. N., Totten, T. L., Bridges, T. L., \& Jennings, M. (2010). Examining teachers' beliefs about African American male students in a low-performing high school in an African American school district. Teachers College Record, 112, 289-330.

Midgley, C., Kaplan, A., Middleton, M., Urdan, T., Maehr, M. L., Hicks, L., . . Roeser, R. W. (1998). Development and validation of scales assessing students' achievement goal orientation. Contemporary Educational Psychology, 23, 113-131. doi:10.1006/ceps.1998.0965

Morgan, S. L., \& Mehta, J. D. (2004). Beyond the laboratory: Evaluating the survey evidence for the disidentification explanation of Black-White differences in achievement. Sociology of Education, 77, 82-101. doi:10. $1177 / 003804070407700104$

Muthén, B., \& Muthén, L. (2010). Mplus user's guide (6th ed.). Los Angeles, CA: Author.

Nasir, N. S., \& Cooks, J. (2009). Becoming a hurdler: How learning settings afford identities. Anthropology $\mathcal{E}$ Education Quarterly, 40, 41-61. doi:10.1111/j.1548-1492.2009. 01027.x

Nasir, N. S., Jones, A., \& McLaughlin, M. (2011). School connectedness for students in low-income urban high schools. Teachers College Record, 113, 1755-1793.

O'Connor, C. (1997). Dispositions toward (collective) struggle and educational resilience in the inner city: A case analysis of six African American high school students. American Educational Research Journal, 34, 593-629. doi:10.3102/00028312034004593

Ogbu, J. U. (1978). Minority education and caste: The American system in cross-cultural perspective. New York, NY: Academic Press.

Ogbu, J. U. (1991). Minority coping responses and school experience. Journal of Psychohistory, 18, 433-456.

Ogbu, J. U. (2003). Black American students in an affluent suburb: A study of academic disengagement. Mahwah, NJ: Erlbaum.

Osborne, J. W., \& Jones, B. D. (2011). Identification with academics and motivation to achieve in school: How the structure of the self influences academic outcomes. Educational Psychology Review, 23, 131-158. doi:10.1007/ s10648-011-9151-1

Oyserman, D. (2007). Social identity and self-regulation. In A. W. Kruglanski \& E. T. Higgins (Eds.), Social psychology: Handbook of basic principles (2nd ed., pp. 432453). New York, NY: Guilford Press.

Paris, S. G., Byrnes, J. P., \& Paris, A. H. (2001). Constructing theories, identities, and actions of self-regulated learners. In B. Zimmerman \& D. Schunk (Eds.), Self-regulated learning and academic achievement (pp. 253-287). New York, NY: Springer-Verlag.

Paris, S. G., \& Paris, A. H. (2001). Classroom applications of research on self-regulation learning. Educational Psychologist, 36, 89-101. doi:10.1207/S153269985EP 3602_4

Pintrich, P. R. (2000). The role of goal orientation in selfregulated learning. In M. Boekaerts, P. R. Pintrich, \& M. Zeidner (Eds.), Handbook of self-regulation (pp. 452-502). 
San Diego, CA: Academic Press. doi:10.1016/ B978-012109890-2/50043-3

Pintrich, P. R., \& De Groot, E. V. (1990). Motivational and self-regulated learning components of classroom academic performance. Journal of Educational Psychology, 82, 33-40. doi:10.1037/ /0022-0663.82.1.33

Preacher, K. J., Rucker, D. D., \& Hayes, A. F. (2007). Addressing moderated mediation hypotheses: Theory, methods and prescriptions. Multivariate Behavioral Research, 42, 185-227. doi:10.1080/00273170701341316

Roderick, M. (2003). What's happening to the boys? Early high school experiences and school outcomes among African American male adolescents in Chicago. Urban Education, 38, 538-607. doi:10.1177/0042085903256221

Sanchez, B., Colon, Y., \& Esparza, P. (2005). The role of sense of school belonging and gender in the academic adjustment of Latino adolescents. Journal of Youth and Adolescence, 34, 619-628.

Schachter, E. P., \& Rich, Y. (2011). Identity education: A conceptual framework for educational researchers and practitioners. Educational Psychologist, 46, 222. doi:10. 1080/00461520.2011.614509

Schunk, D., \& Ertmer, P. (2000). Self-regulation and academic learning: Self-efficacy enhancing interventions. In M. Boekaerts, P. Pintrich, \& M. Zeidner (Eds.), Handbook of self-regulation (pp. 631-649). San Diego, CA: Academic Press.

Schunk, D. H., \& Pajares, F. (2004). Self-efficacy in education revisited: Empirical and applied evidence. In D. M. McInerney, \& S. Van Etten (Eds.), Big theories revisited (pp. 115-138). Greenwich, CT: Information Age.

Singh, K., Chang, M., \& Dika, S. (2010). Ethnicity, selfconcept, and school belonging: Effects on school engagement. Educational Research for Policy E Practice, 9, 159-175. doi:10.1007/s10671-010-9087-0

Smalls, C., White, R., Chavous, T., \& Sellers, R. (2007). Racial ideological beliefs and racial discrimination experiences as predictors of academic engagement among African American adolescents. Journal of Black Psychology, 33, 299-330. doi:10.1177/0095798407302541

Spencer, M. B., Noll, E., Stoltzfus, J., \& Harpalani, V. (2001). Identity and school adjustment: Questioning the "acting White" assumption. Educational Psychologist, 36, 21-30.

Stearns, E., \& Glennie, E. J. (2006). When and why dropouts leave high school. Youth and Society, 38, 29-29. doi:10.1177/0044118X05282764

Steele, C. M. (1997). A threat in the air: How stereotypes shape intellectual identity and performance. American Psychologist, 52, 613-629. doi:10.1037/0003-066X.52.6. 613

Taylor, A. Z., \& Graham, S. (2007). An examination of the relationship between achievement values and perceptions of barriers among low-SES African American and Latino students. Journal of Educational Psychology, 99, 52-64. doi:10.1037/0022-0663.99.1.52

Thomas, D., \& Stevenson, H. C. (2009). Gender risks and education: The particular classroom challenges of urban, low-income African American boys. Review of Research in Education, 33, 160-180. doi:10.3102/0091732X08327164

Tyson, K., Darity, W., Jr., \& Castellino, D. (2005). “It's not a Black thing": Understanding the burden of acting White and other dilemmas of high achievement. American Sociological Review, 70, 582-605.

Voelkl, K. E. (1996). Measuring students' identification with school. Educational and Psychological Measurement, 56, 760-770. doi:10.1177/0013164496056005003

Voelkl, K. E. (1997). Identification with school. American Journal of Education, 105, 294-318. doi:10.1086/444158

Walton, G. M., \& Cohen, G. L. (2011). A brief socialbelonging intervention improves academic and health outcomes of minority students. Science, 331, 1447-1451.

Wigfield, A., \& Cambria, J. (2010). Students' achievement values, goal orientations, and interest: Definitions, development, and relations to achievement outcomes. Developmental Review, 30, 1-35.

Wigfield, A., \& Eccles, J. S. (2000). Expectancy-value theory of achievement motivation. Contemporary Educational Psychology, 25, 68-81. doi:10.1006/ceps.1999.1015

Wigfield, A., \& Eccles, J. S. (2002). The development of competence beliefs, expectancies for success, and achievement values from childhood through adolescence. In A. Wigfield \& J. Eccles (Eds.), Development of achievement motivation (pp. 91-120). San Diego, CA: Academic Press.

Witherspoon, D., \& Ennett, S. (2011). Stability and change in rural youths' educational outcomes through the middle and high school years. Journal of Youth and Adolescence, 40, 1077-1090. doi:10.1007/s10964-0109614-6

Wolters, C. A., Pintrich, P. R., \& Karabenick, S. A. (2003). Assessing academic self-regulated learning. In C. A. Moore \& L. H. Lipman (Eds.), What do children need to flourish? Conceptualizing and measuring indicators of positive development. Washington, DC: Springer.

Wong, C. A., Eccles, J. S., \& Sameroff, A. (2003). The influence of ethnic discrimination and ethnic identification on African American adolescents' school and socioemotional adjustment. Journal of Personality, 71, 1197-1232.

Wright, B. L. (2011). I know who I am, do you? Identity and academic achievement of successful African American male adolescents in an urban pilot high school in the United States. Urban Education, 46, 61-638. doi:10. $1177 / 0042085911400319$

Zimmerman, B. J., Bandura, A., \& Martinez-Pons, M. (1992). Self-motivation for academic attainment: The role of self-efficacy beliefs and personal goal setting. American Educational Research Journal, 29, 663-676. doi:10.3102/00028312029003663

Zimmerman, B. J., \& Kitsantas, A. (2005). The hidden dimension of personal competence: Self-regulated learning and practice. In A. J. Elliot \& C. Dweck (Eds.), Handbook of competence and motivation (pp. 509-526). New York, NY: Guilford Press. 